\title{
Assessment of histological liver alterations in dogs naturally infected with Leishmania infantum
}

Isadora S. Lima ${ }^{*}$, Manuela S. Solcá1, Wagner L. Tafuri ${ }^{2}$, Luiz A. R. de Freitas ${ }^{1}$ and Washington L. C. dos-Santos ${ }^{1}$

\begin{abstract}
Background: The liver plays a central role in the development of canine visceral leishmaniasis. Studies of natural infection in animals and humans indicate a direct relationship between resolution of infection and the formation and maturation of granulomas in the liver. However, in contrast to other reports in the literature, the present study found no differences in the characteristics of hepatic granulomas that could be related to resistance or susceptibility to Leishmania. Here, we describe the hepatic alterations observed in dogs with differing clinical manifestations of visceral leishmaniasis in an endemic area in the state of Bahia, Brazil.
\end{abstract}

Methods: We examined 148 animals in an endemic area. The animals were clinically examined, and the infection was determined by ELISA, spleen aspirate culture and quantitative PCR. The animals were grouped into asymptomatic or symptomatic based on the number of signs of LV. The histological liver evaluation was performed in a blinded way.

Results: Our results indicated no association between the characteristics of granulomas and clinical presentation. We found an association between the intensity of this inflammatory response and parasite load in the animals' spleens. It is important to note that while hepatic alterations, such as portal and perivascular inflammation and the presence of larger amounts of granulomas, were linked with higher parasite loads, we found the inverse to be true with respect to intrasinusoidal lymphocytosis, the formation of intrasinusoidal inflammatory cell aggregates and Kupffer cell hypertrophy.

Conclusions: Our findings suggest that the presence of mononuclear inflammatory cells inside the sinusoids is more important than that of organized granulomas in terms of the containment of parasitism by the host. We suggest that the presence of granulomas indicates the failure of a first line of defense mechanism in the control of parasite infection, which could be related to the presence of inflammatory cells and Kupffer cell hypertrophy inside the sinusoids. We further demonstrated that dogs with active Leishmania spp. infection present a higher frequency of inflammatory changes in the liver. In addition to being correlated with the severity of clinical manifestation, these hepatic alterations were also associated with changes in hematological and biochemical parameters.

Keywords: Leishmania infantum, Canine visceral leishmaniasis, Liver histopathology, Pathology, Inflammation, Granuloma

\footnotetext{
*Correspondence: isadoraslima@hotmail.com

${ }^{1}$ Instituto Gonçalo Moniz, Fundação Oswaldo Cruz, Salvador, BA, Brazil

Full list of author information is available at the end of the article
} 


\section{Background}

Visceral leishmaniasis (VL), a zoonosis with a high prevalence and broad distribution throughout the world, is caused by the protozoan Leishmania infantum [1, 2]. Dogs are considered the main reservoir of VL as they harbor parasites in the skin, thereby facilitating the infection of sand flies $[3,4]$. In addition to the dog's importance in the epidemiology of VL, the study of canine VL can contribute to the understanding of human disease, since some clinical features, histopathological alterations and disease evolution bear similarities with the human form [5-9].

In humans, different patterns of inflammatory response in the liver have been associated with susceptibility or resistance to VL infection. In susceptible persons, liver alterations include hypertrophy and hyperplasia of Kupffer cells, variable parasitism in these cells, as well as in macrophages in portal tracts, mononuclear cell inflammatory infiltrate in the portal tract and parenchyma, the ballooning of hepatocytes and pericellular fibrosis [10, 11]. Scarce data are available concerning hepatic changes in asymptomatic patients. In the course of an outbreak in Italy, Pampiglione et al. [12,13] biopsied the livers of five asymptomatic patients with positive DTH for Leishmania antigens and observed intralobular granulomas consisting of accumulations of epithelioid macrophages, histiocytes, lymphocytes, plasma cells and rare eosinophils. This same granulomatous inflammatory pattern in the liver has been correlated with resistance in non-susceptible mice $[14,15]$.

The liver alterations arising from canine VL in naturally infected dogs are akin to those seen in humans. In symptomatic animals, parasitism, inflammatory changes, hyperplasia and hypertrophy of Kupffer cells occur more intensely than in asymptomatic or oligosymptomatic animals [16]. Granulomas of variable size, consisting of macrophages parasitized or not with Leishmania, epithelioid cells, small numbers of lymphocytes, plasma cells and rare neutrophils are also described [16-19]. Sánchez et al. [19] reported well-organized granulomas in the livers of asymptomatic dogs that mounted a T-cell memory immune response, in contrast to the disorganized granulomas and intense parasitism of Kupffer cells seen in symptomatic animals. These authors' findings reinforced the notion that different patterns of inflammatory response correlate with differences in resistance and susceptibility.

An aspect worth considering is that most studies addressing the changes observed in the livers of dogs with visceral leishmaniasis employ experimental models or cases showing extreme poles of the disease, i.e. either asymptomatic or severe clinical manifestations. Although such data are of great importance for the understanding of $\mathrm{VL}$, in fact there exists a wide spectrum of alterations, ranging from cases of subclinical disease with minimal changes to extreme cases that evolve to death, while intermediate cases are crucially important to the general context of this disease. Semi-domiciled and street dogs are largely present in areas endemic for visceral leishmaniasis, such as the area in which our study was conducted. Understanding the inflammatory response and outcome of infection in these animals is essential to the overall understanding of this disease, and can be of great value in the adoption of disease control strategies in these areas, such as immunoprophylaxis.

The present study describes changes in the liver observed in dogs with differing clinical manifestations of visceral leishmaniasis in an endemic area in the State of Bahia, Brazil. Herein we correlate the observed histological hepatic alterations with the severity of clinical manifestations and parasite culture positivity.

\section{Methods \\ Animals}

The samples and clinical and laboratory data used in this study were obtained from 148 stray dogs of different breeds and different estimated ages collected from areas around the municipalities of Jequié and Camaçari (Bahia, Brazil), both areas endemic for visceral leishmaniasis, in 2004, 2006, 2010 and 2012. This study was performed in collaboration with the Endemic Diseases Surveillance Programme of the Bahia State Health Secretariat, which is responsible for the surveillance and control of visceral leishmaniasis. All animals were clinically examined by at least two veterinarians. The presence of anti-Leishmania antibodies in the sera was determined by ELISA. Dogs with a positive result by ELISA, as well as those who were not claimed by owners, were kept in a kennel for $48 \mathrm{~h}$ with free access to food and water. These 148 dogs were then sedated with acepromazine $(0.1 \mathrm{mg} / \mathrm{kg}$ intravenous (iv), Acepram 1\%; Vetnil, Louveira, Brazil) and sodium thiopental (15 mg/kg iv, Thiopentax $1 \mathrm{~g}$; Cristália, São Paulo, Brazil) and euthanized, as mandated per Brazilian Ministry of Health Surveillance Programme protocols, using a saturated solution of potassium chloride $(2 \mathrm{ml} / \mathrm{kg}$, iv). Immediately following euthanasia, spleen aspirates were collected for culture and quantitative PCR, and liver and spleen samples were fixed in formalin and embedded in paraffin for morphological studies. The technical details of the anti-Leishmania ELISA, splenic culture for Leishmania isolation and quantitative PCR have been reported elsewhere [9, 20].

\section{ELISA}

Briefly, 96-well plates were sensitized with crude antigen obtained from L. infantum. Plates were washed, blocked 
with PBS containing 10\% skimmed milk, and the serum of each animal was applied at a dilution of 1:400, followed by an anti-dog total IgG peroxidase conjugate (SigmaAldrich, San Luis, USA). The enzymatic reaction was developed with tetramethyl benzidine (Sigma-Aldrich). A cut-off was established using serum samples obtained from 48 animals from the municipalities of Porto Alegre (Rio Grande do Sul, Brazil) and Salvador (Bahia, Brazil), both non-endemic areas for visceral leishmaniasis. ELISA results were considered positive when higher than the mean plus three standard deviations (SD) of values obtained from 48 healthy dogs.

\section{Real-time PCR for the detection of Leishmania, Ehrlichia and Babesia DNA}

To detect parasite DNA in frozen spleen samples, DNA was extracted using a DNeasyH Blood and Tissue Kit (Qiagen, Hilden, Germany) in accordance with the manufacturer's protocols. Once extracted, the quality and concentration of each DNA sample was determined using a digital spectrophotometer (NanoDropH ND-1000; Thermo Fisher Scientific, Waltham, USA). The DNA samples were then adjusted to a concentration of $30 \mathrm{ng} /$ $\mathrm{ml}$, aliquoted and stored at $-20{ }^{\circ} \mathrm{C}$ until use. Real-time PCR assays were performed using a previously described amplification procedure [21]. Reactions were performed in a final volume of $25 \mathrm{ml}$ containing $5 \mathrm{ml}$ of the DNA sample diluted to $30 \mathrm{ng} / \mathrm{ml}$ in deionized water and $20 \mathrm{ml}$ of PCR mixture. The PCR mixture consisted of $12.5 \mathrm{ml}$ of Universal Mastermix (Applied Biosystems, Carlsbad, CA, USA), $900 \mathrm{nM}$ each of the forward primer LEISH-1 (5'-AAC TTT TCT GGT CCT CCG GGT AG-3'), the reverse primer LEISH-2 (5'-ACC CCC AGT TTC CCG CC-3') and a fluorogenic probe (5'-AAA AAT GGG TGC AGA AAT-3'), which was synthesized using a FAM reporter molecule attached to the $5^{\prime}$ end and a MGBNFQ quencher linked to the $3^{\prime}$ end (Applied Biosystems), at a final concentration of $200 \mathrm{nM}$. A standard curve was generated using serial dilutions of $L$. infantum DNA from 106 to 1021 parasites/ml, with each dilution performed in triplicate. The amplifications were performed in triplicate for each sample and for the negative control using an ABI Prism 5900 sequence detection system (Applied Biosystems). A canine housekeeping gene (18S rRNA) was amplified to normalize concentrations of the input sample DNA. Parasite load was expressed as the number of parasites normalized to the established reference amplification value for the $18 \mathrm{~S}$ rRNA housekeeping gene in $100 \mathrm{mg}$ of host tissue.

To detect Ehrlichia canis DNA in frozen spleen samples, this same protocol was used for DNA extraction, with reactions performed following the protocol described by Bulla et al. [22].

\section{Clinical data}

All animals were subjected to a clinical examination, emphasizing parameters considered indicative of canine visceral leishmaniasis, as defined by Lima et al. [9]. The animals were grouped into two categories according to the recorded clinical signs suggestive of visceral leishmaniasis: asymptomatic (absence of clinical signs) or symptomatic (presence of any clinical signs related to visceral leishmaniasis).

\section{Biochemistry and hematology}

Blood samples for hematological and biochemical analyses were collected from each dog's cephalic vein under manual restraint. Samples were preserved in EDTA-2Na tubes (Greiner Bio-one, Kremsmünster, Austria) and in blood collection tubes (BD VacutainerH; Becton Dickinson, Franklin Lakes, USA) and examined on the same day. Total red blood cell (RBC) and white blood cell (WBC) counts were obtained using an automated cell counter (Pentra 80 counter; ABX Diagnostics, Montpellier, France). Part of the collected blood was transferred to microhematocrit tubes and centrifuged at $290 \times g$ for 5 min for hematocrit estimation. Differential blood cell counts were also performed. Serum collected by centrifugation in VacutainerH tubes was used for the following biochemical tests using an enzymatic colorimetric method on an A15 auto-analyzer (BioSystems, Barcelona, Spain): total protein (TP), albumin, aspartate aminotransferase (AST), alanine aminotransferase (ALT), total bilirubin, alkaline phosphatase, urea and creatinine.

\section{Histological examination}

Liver samples were fixed in $10 \%$ formaldehyde, dehydrated in graded alcohol, clarified in xylene and embedded in paraffin. Histological sections were cut at a thickness of $4.0 \mu \mathrm{m}$ and stained by hematoxylin-eosin (H\&E) for analysis under conventional light microscopy. Two pathologists (LARF and WLCS) examined all samples. Histological examinations considered the following hepatic alterations: the presence of portal inflammation, central perivenular inflammation (zone 3 of the Rappaport acini), inflammatory cell aggregates within the sinusoids, portal tract granulomas, intralobular granulomas, as well as Kupffer cell hypertrophy, Kupffer cell hyperplasia, sinusoidal congestion and dilatation, intrasinusoidal lymphocytosis, hepatocellular steatosis, ballooning of hepatocytes, hepatocellular necrosis and apoptosis. These aspects were evaluated and classified as absent, mild (score: 1 , small aggregates in a small proportion of less than $30 \%$ of the examined $\times 400$-magnified microscopic fields), moderate (score: 2 , aggregates observed in $30-60 \%$ of the examined $\times 400$-magnified microscopic 
fields) or intense (score: 3 , aggregates seen in over $60 \%$ of the examined $\times 400$-magnified microscopic fields). A histological score for each animal was calculated by the sum of all observed alterations.

Immunohistochemistry was performed to identify amastigote forms of Leishmania in the livers of 20 animals, following a protocol described by Tafuri et al. [23]. Slides were evaluated and the same scoring method described above was applied to grade the presence of amastigote forms of Leishmania in the liver.

\section{Analysis and expression of results}

Data were analyzed using STATA Statistics/Data Analysis v.11.0, GraphPad Prism v.5.02 and Microsoft Excel 2013 software. Results are expressed in absolute or relative values. Differences among groups were evaluated by the Kruskal-Wallis test and Dunn's multiple comparison test to compare between two groups. For comparisons involving proportions, Fisher's exact test was used. Results were considered significant if $P<0.05$.

\section{Results}

The clinical and laboratory characteristics of the 148 animals included in this study are presented in Table 1.

\section{Histological changes in the liver}

Mild (61\%), moderate (28\%) or intense (4\%) inflammatory infiltrate consisting predominantly of mononuclear cells was present in the portal tracts of 139 (94\%) animals (Fig. 1a, b). In 30 (20\%) dogs, the portal inflammatory infiltrate had a granulomatous aspect, characterized by the presence of epithelioid cells surrounded by lymphocytes (Fig. 1c). Inflammatory infiltrate consisting of macrophages, lymphocytes and plasma cells was found to be prominent around the centrilobular vein (Fig. 1d). Intralobular granulomas were dispersed throughout the hepatic parenchyma (Fig. 1e, f), varying from loosely organized structures composed of Kupffer cells, which were occasionally parasitized, lymphocytes and plasma cells, to well-organized concentric Kupffer cells surrounded by lymphocytes and rare plasma cells (Fig. 1e, f). Kupffer cell hypertrophy and hyperplasia, as well as steatotic and/or ballooned hepatocytes, were also observed (Fig. 1g-i). The main histological findings observed in the canine liver samples are presented in Fig. 1.

\section{Correlations between histological hepatic alterations and spleen parasitism}

Portal tract inflammation (OR: 16.06, CI: 0.9089-283.8, $P=0.0077$ ), portal tract granulomas (OR: 6.727, CI: 2.551-17.74, $P<0.0001$ ) and hepatocyte ballooning (OR: 2.614, CI: $1.148-5.952, P=0.0256)$ were more frequent in dogs with positive spleen culture than in those without
Table 1 Clinical and laboratory characteristics of the sample

\begin{tabular}{|c|c|c|}
\hline & Frequency & $\%$ \\
\hline N & 148 & 100 \\
\hline \multicolumn{3}{|l|}{ Sex } \\
\hline Male & 84 & 57 \\
\hline Female & 64 & 43 \\
\hline \multicolumn{3}{|l|}{ Estimated age (years) } \\
\hline $0-2$ & $16 / 106$ & 15 \\
\hline $3-5$ & $73 / 106$ & 69 \\
\hline$\geq 6$ & $17 / 106$ & 16 \\
\hline \multicolumn{3}{|l|}{ Size } \\
\hline Small & $36 / 146$ & 25 \\
\hline Medium & $85 / 146$ & 58 \\
\hline Large & $25 / 146$ & 17 \\
\hline \multicolumn{3}{|l|}{ Clinical category } \\
\hline Asymptomatic & 15 & 10 \\
\hline Symptomatic & 133 & 90 \\
\hline \multicolumn{3}{|l|}{ ELISA } \\
\hline Negative & 27 & 18 \\
\hline Positive & 118 & 80 \\
\hline Grey zone & 3 & 2 \\
\hline \multicolumn{3}{|l|}{ Culture } \\
\hline Negative & 81 & 55 \\
\hline Positive & 67 & 45 \\
\hline \multicolumn{3}{|l|}{ PCR } \\
\hline Negative & $8 / 135$ & 6 \\
\hline Positive & $127 / 135$ & 94 \\
\hline \multicolumn{3}{|l|}{ Leishmanin skin test } \\
\hline Negative & $75 / 85$ & 88 \\
\hline Positive & $10 / 85$ & 12 \\
\hline Positive in one test & 35 & 24 \\
\hline Positive in all tests & 52 & 35 \\
\hline \multicolumn{3}{|l|}{ Co-infections } \\
\hline Ehrlichiosis & $39 / 57$ & 68 \\
\hline Babesiosis & $12 / 56$ & 21 \\
\hline \multicolumn{3}{|l|}{ Positive ELISA results } \\
\hline Asymptomatic & 10 & 67 \\
\hline Symptomatic & 112 & 84 \\
\hline \multicolumn{3}{|c|}{ Positive culture results } \\
\hline Asymptomatic & 3 & 20 \\
\hline Symptomatic & 65 & 49 \\
\hline
\end{tabular}

Abbreviation: $\mathrm{N}$, absolute number. The denominator varies according to the availability of the recorded data

positivity (Fisher's exact test, Table 2). No statistically significant differences were detected with regard to the frequency of other morphological alterations among the groups.

The mean histological scores were higher in the dogs with positive splenic aspirate culture than in dogs without positivity (Mann-Whitney test, $U=2108, Z=2.36$, $P=0.0184$, Fig. 2). Furthermore, splenic parasite burden was higher in animals with intense portal inflammation 

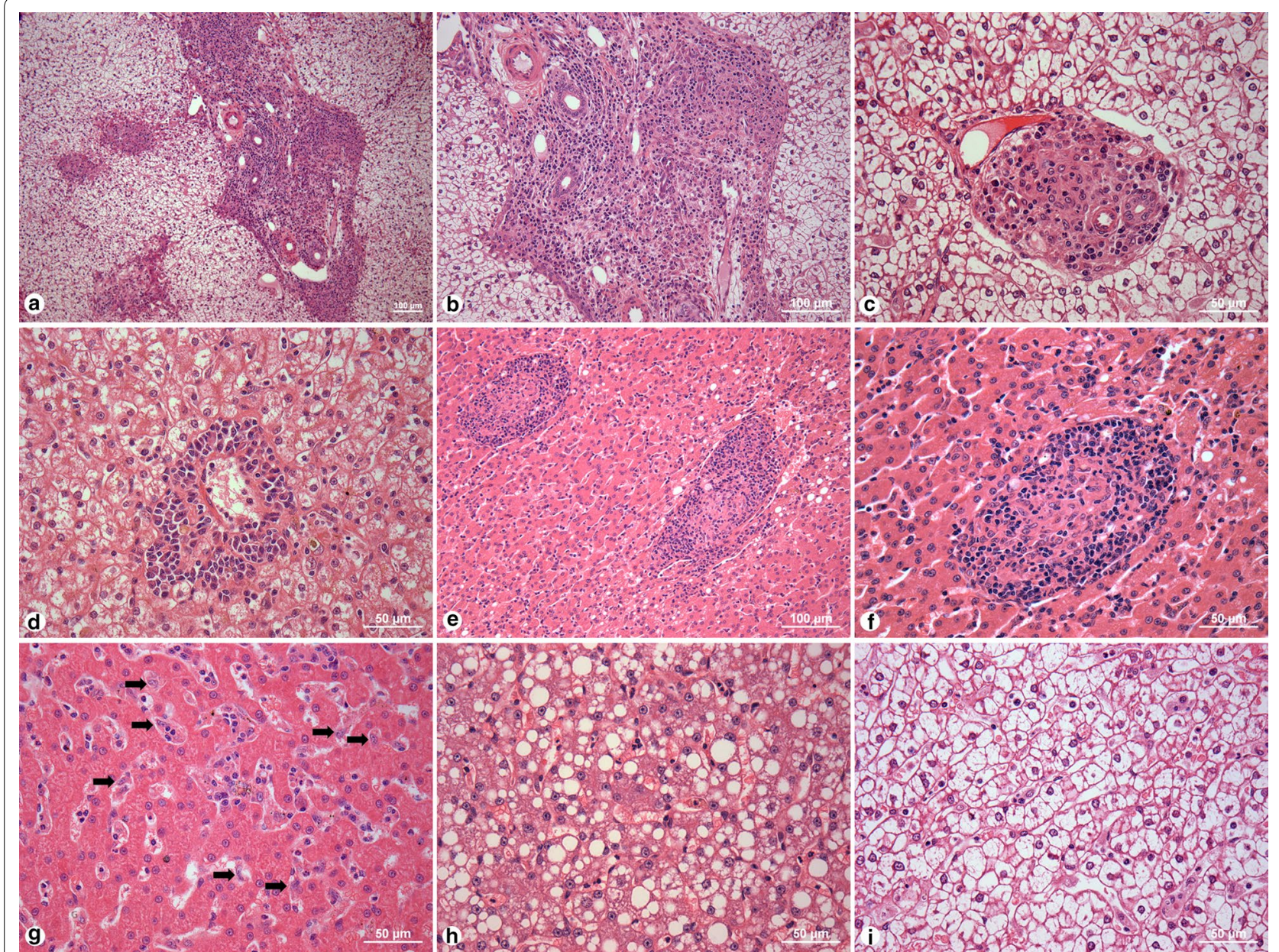

Fig. 1 Histological changes in the liver of dogs with Leishmania infection. a, b Portal tract chronic inflammation. c Portal tract granuloma. d Perivascular inflammation. e, $\mathbf{f}$ Intralobular granuloma. $\mathbf{g}$ Hyperplasia and hypertrophy of Kupffer cells. $\mathbf{h}$ Steatosis. i Ballooning. Scale-bars: $\mathbf{a}, \mathbf{b}, \mathbf{e}$, $100 \mu \mathrm{m} ; \mathbf{c}, \mathbf{d}, \mathbf{f}-\mathbf{i}, 50 \mu \mathrm{m}$

(Mann-Whitney test, $U=21.00, Z=2.39, P=0.0169$ ), intense central perivascular inflammation (Mann-Whitney test, $U=0.0, Z=3.02, P=0.0025)$ and a higher frequency of intralobular (Mann-Whitney test, $U=90.00$, $Z=2.51, P=0.0120$ ) and portal granulomas (MannWhitney test, $U=33.00, Z=2.30, P=0.0215$, Fig. 3). Conversely, higher splenic parasite loads were inversely correlated with intrasinusoidal lymphocytosis (MannWhitney test, $U=73.00, Z=2.39, P=0.0169)$, the presence of intrasinusoidal inflammatory cell aggregates (Mann-Whitney test, $U=39.00, Z=2.23, P=0.0256$ ) and Kupffer cell hypertrophy (Mann-Whitney test, $U=718.5$, $Z=2.41, P=0.0161$, Fig. 3).

\section{Liver granulomas}

Granulomas were classified as disorganized when formed by ill-defined aggregates of epithelioid cells, and well-organized when formed by rounded aggregates consisting of more than 10 epithelioid macrophages. Both types of granulomas showed parasitized macrophages. Lymphocytes and plasma cells were frequently present in well-organized granulomas. Sixteen out of 20 dogs presented granulomas in the liver. Six had organized granulomas and 10 had disorganized granulomas. Among the dogs with organized granulomas, one showed few parasites inside macrophages, two presented intense parasitism, and no amastigotes were observed in the livers of the three remaining animals. In the 10 animals with disorganized granulomas, histological parasitism was scored as mild in three, moderate in two and severe in one dog. No amastigotes were observed in four animals. No statistically significant differences in histological parasitism were detected among the animals with either organized or disorganized granulomas. 
Table 2 Histological alterations in the livers of dogs with and without positive splenic aspirate culture

\begin{tabular}{llc}
\hline Histological alteration & With positive splenic aspirate culture $(N=68)$ & $\begin{array}{l}\text { Without positive splenic } \\
\text { aspirate culture (N=80) } \\
n(\%)\end{array}$ \\
\hline Portal inflammation & $n(\%)$ & $72(90)$ \\
Intrasinusoidal granulomas & $67(99)^{* *}$ & $43(54)$ \\
Kupffer cell hyperplasia & $44(65)$ & $55(69)$ \\
Kupffer cell hypertrophy & $43(63)$ & $51(64)$ \\
Portal granulomas & $39(57)$ & $6(8)$ \\
Intrasinusoidal lymphocytosis & $24(35)^{* * *}$ & $64(80)$ \\
Congestion of sinusoids & $51(75)$ & $13(16)$ \\
Dilation of sinusoids & $8(12)$ & $17(21)$ \\
Intrasinusoidal aggregates & $10(15)$ & $47(59)$ \\
Perivascular inflammation & $38(56)$ & $74(93)$ \\
Hepatocyte steatosis & $66(97)$ & $14(18)$ \\
Ballooning of hepatocytes & $14(21)$ & $11(14)$ \\
Hepatocyte necrosis & $20(29)^{*}$ & $15(19)$
\end{tabular}

${ }^{*} P<0.05,{ }^{* *} P<0.01,{ }^{* * *} P<0.005$

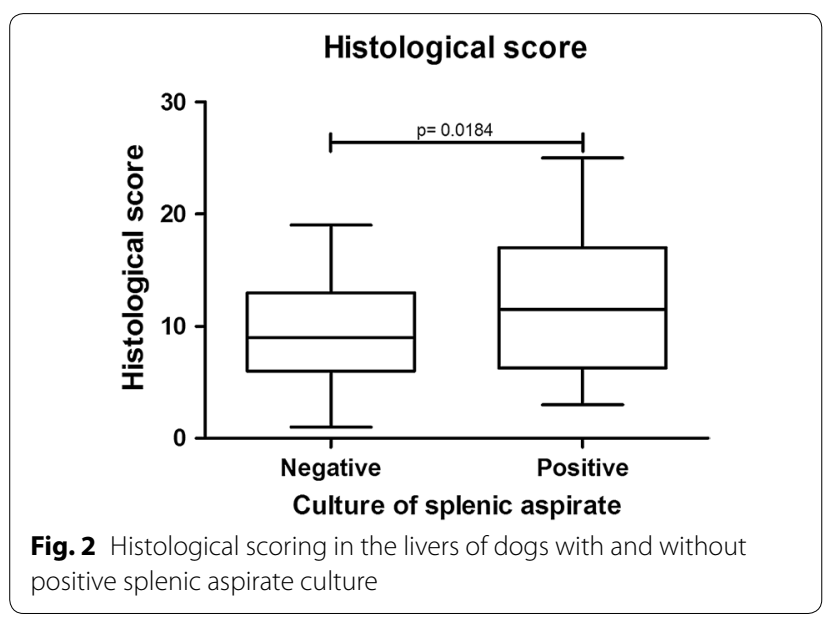

\section{Histological parasitism in the liver}

Leishmania amastigotes were detected by immunohistochemistry in the livers of $10 / 20$ (50\%) animals with different clinical profiles. Histological parasitism was mild in six (30\%), moderate in two (10\%) and intense in another two (10\%, Fig. 4). No statistically significant associations were detected between histological parasitism and the frequency of the other liver histological alterations evaluated.

\section{Associations between histological alterations and clinical manifestations}

As shown in Table 3, animals with symptomatic infection and a positive spleen culture were more likely to present portal inflammation (OR: 3.7, CI: 1.99-6.7), intralobular granulomas (OR: $1.55, \mathrm{CI}: 1.1-2.2$ ), portal granulomas (OR: 3.66, CI: 1.8-7.3), perivascular inflammation (OR: 2.76, CI: 1.6-4.8) and hepatocyte ballooning (OR: 1.88, CI: 1.2-2.9) than dogs with asymptomatic infection or those with a negative spleen culture. No statistically significant differences were detected in relation to the other alterations evaluated.

In addition, animals with active symptomatic infection presented higher histological scores than dogs with a negative spleen culture, regardless of symptomatic (Mann-Whitney test, $U=1718, Z=2.22, P=0.265$ ) or asymptomatic status (Mann-Whitney test, $U=246.5$, $Z=2.01, P=0.0442$, Fig. 5).

\section{Associations between hepatic histological alterations and laboratory parameters}

$\mathrm{RBC}$ counts were lower in animals with intense portal and perivascular inflammation than in animals with mild portal inflammation (Mann-Whitney test, $U=6.000, Z=2.54, P=0.0111$ ) or mild perivascular inflammation (Mann-Whitney test, $U=8.000, Z=2.81$, $P=0.0049$ ), as well as animals with moderate portal inflammation (Mann-Whitney test, $U=4.000, Z=2.13$, $P=0.0330)$ or moderate perivascular inflammation (Mann-Whitney test, $U=10.00, Z=2.23, P=0.0257$ ). Hemoglobin concentrations were lower in animals with intense portal and perivascular inflammation than in those with mild portal inflammation (Mann-Whitney test, $U=7.500, Z=2.47, P=0.0136$ ) or mild perivascular inflammation (Mann-Whitney test, $U=10.50$, $Z=2.69, \quad P=0.0071)$, as well as in animals with 
Portal tract inflammation

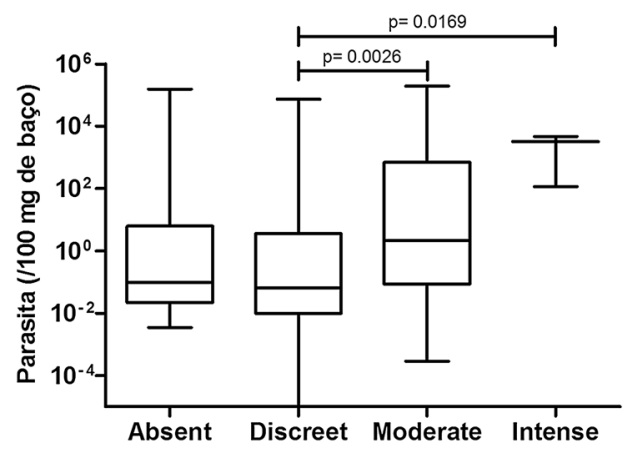

Intralobular granulomas
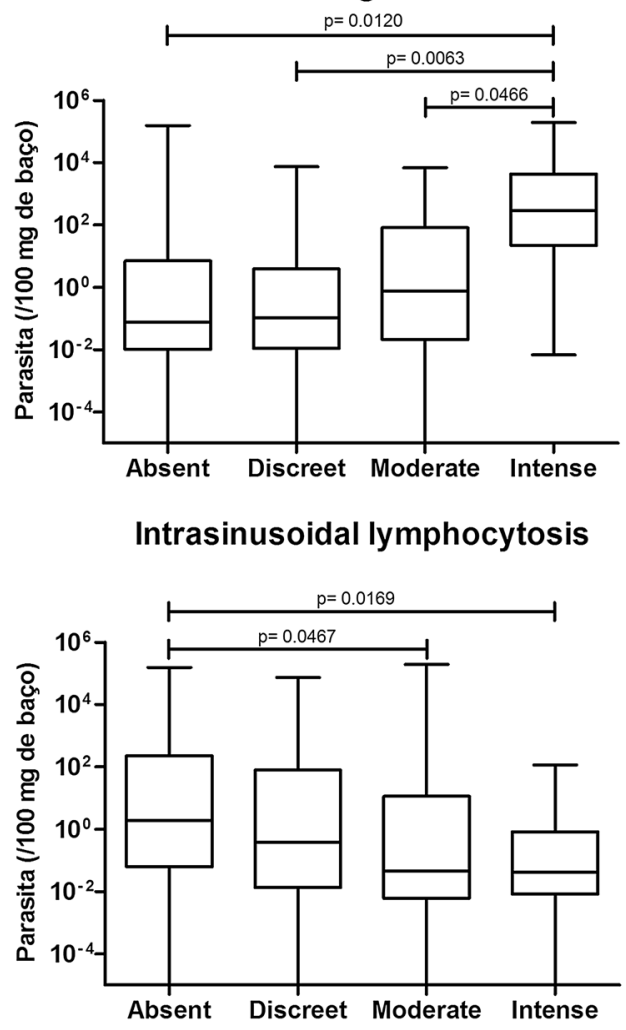

Kupffer cell hypertrophy

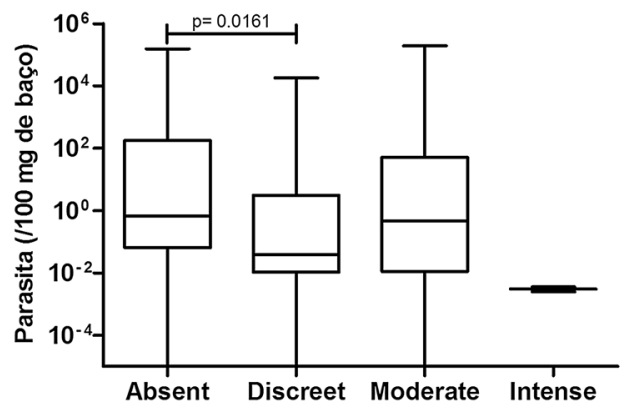

\section{Perivascular central inflammation}

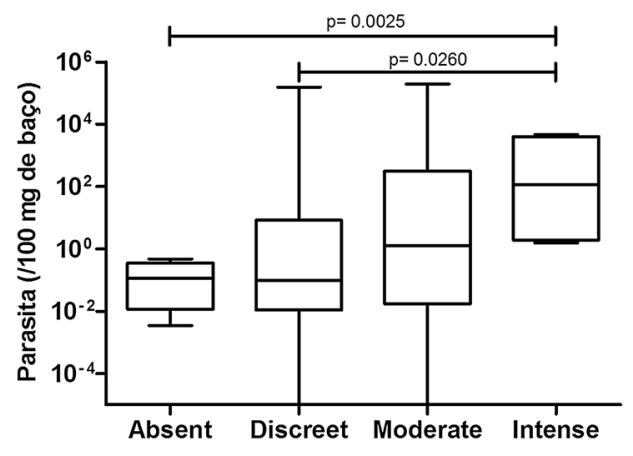

Portal tract granulomas

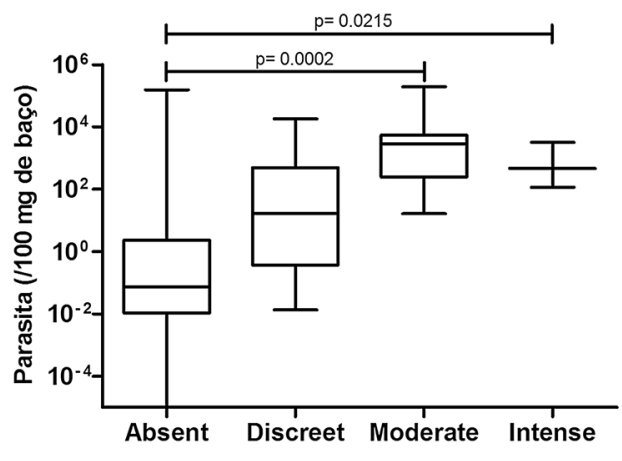

Intrasinusoidal cell aggregates

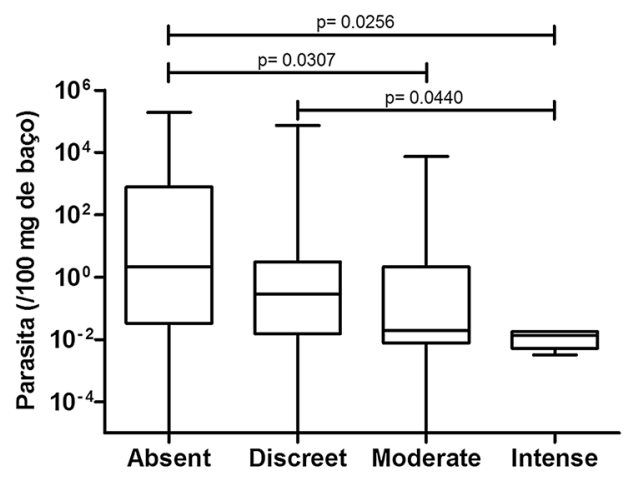

Fig. 3 Associations between the intensity of hepatic histological alterations in the liver and splenic parasitism 

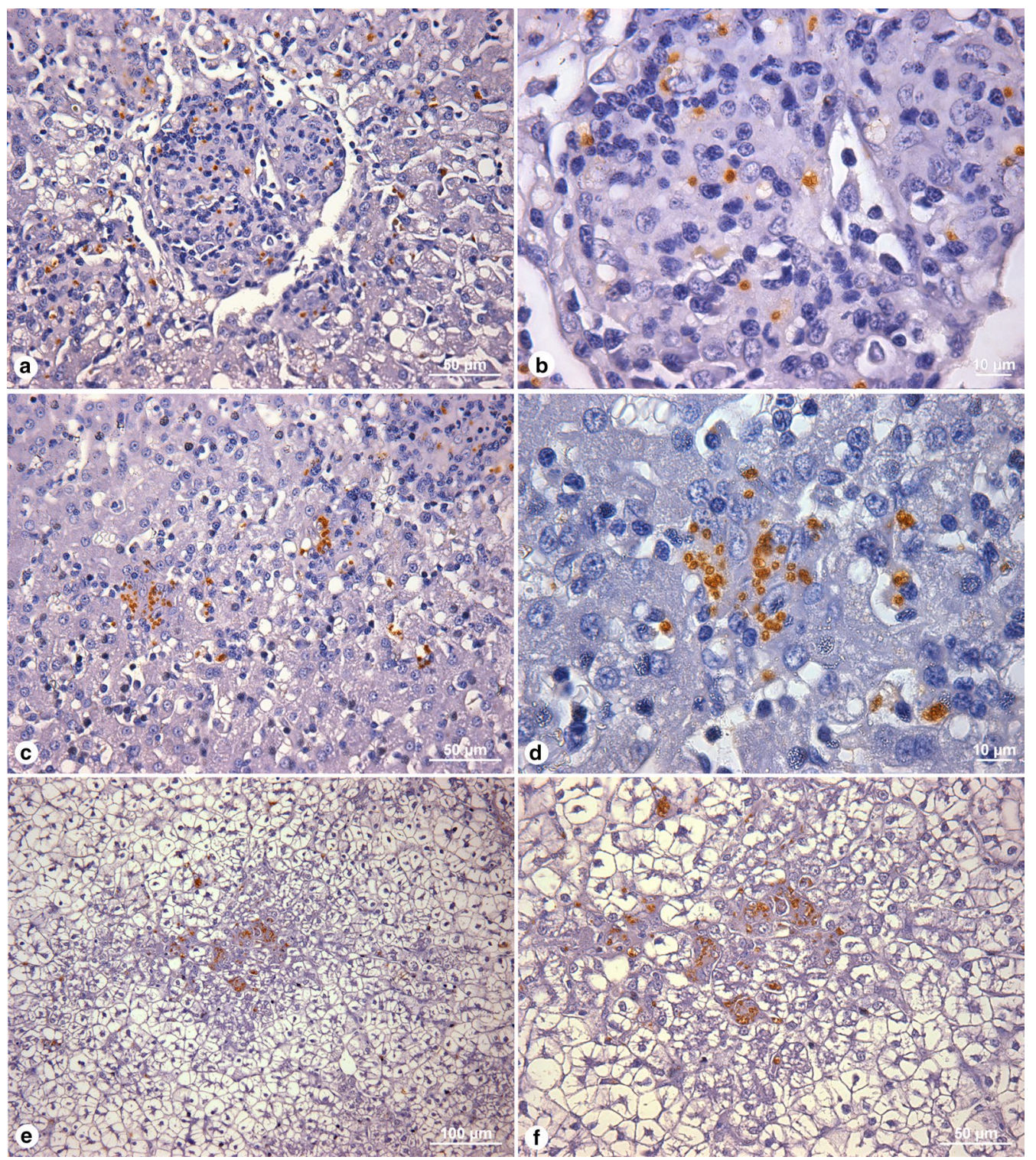

Fig. 4 Histological evaluation of the presence of parasites in the liver by immunohistochemistry. $\mathbf{a}, \mathbf{b}$ Nodular granulomatous lesion containing amastigotes. $\mathbf{c}, \mathbf{d}$ Intracellular amastigotes in Kupffer Cells. e, f Disorganized granuloma containing amastigotes. Scale-bars: a, c, f, 50 m; b, d, $10 \mu \mathrm{m} ; \mathbf{e}, 100 \mu \mathrm{m}$

moderate portal inflammation (Mann-Whitney test, $U=3.000, Z=2.25, P=0.0244$ ) or moderate perivascular inflammation (Mann-Whitney test, $U=7.000$, $Z=2.48, P=0.0133)$. Hematocrit levels were lower in animals with intense portal and perivascular inflammation than in animals with mild portal inflammation (Mann-Whitney test, $U=6.000, Z=2.54, P=0.0111$ ) or mild perivascular inflammation (Mann-Whitney test, $U=7.000, Z=2.86, P=0.0042)$, as well as in animals with moderate portal inflammation (MannWhitney test, $U=4.000, \quad Z=2.13, \quad P=0.0330$ ) or moderate perivascular inflammation (Mann-Whitney test, $U=8.000, Z=2.39, P=0.0167$, Table 4 ).

Serum AST levels were higher in animals with intense portal inflammation than in animals with mild (MannWhitney test, $U=14.00, Z=2.68, P=0.0074$ ) or moderate portal inflammation (Mann-Whitney test, $U=3.000$, $Z=2.73, \quad P=0.0063$, Table 5). Animals with higher numbers (i.e. intense) of intralobular and portal tract granulomas had higher AST levels than animals without intralobular (Mann-Whitney test, $U=29.50, Z=2.62$, $P=0.0087$ ) or portal tract granulomas (Mann-Whitney 
Table 3 Histological alterations in the livers of symptomatic dogs with positive Leishmania culture versus animals with other clinical classifications

\begin{tabular}{llll}
\hline Histological alteration & $\begin{array}{l}\text { Symptomatic with positive culture } \\
(N=65) \\
n(\%)\end{array}$ & $\begin{array}{l}\text { Other classifications } \\
(N=83) \\
n(\%)\end{array}$ & OR (95\% Cl) \\
\hline Portal inflammation & $64(98)$ & $75(90)$ & $3.7(1.99-6.9)^{* *}$ \\
Intralobular granulomas & $42(65)$ & $45(54)$ & $1.55(1.1-2.2)^{*}$ \\
Kupffer cell hyperplasia & $42(65)$ & $56(67)$ & $0.93(0.6-1.4)$ \\
Kupffer cell hypertrophy & $38(58)$ & $52(63)$ & $0.91(0.6-1.3)$ \\
Portal granulomas & $23(35)$ & $7(8)$ & $3.66(1.8-7.3)^{* *}$ \\
Intrasinusoidal lymphocytosis & $50(77)$ & $65(78)$ & $1.02(0.7-1.5)$ \\
Congestion of sinusoids & $14(22)$ & $13(16)$ & $0.83(0.4-1.7)$ \\
Dilation of sinusoids & $10(15)$ & $17(20)$ & $0.82(0.4-1.5)$ \\
Intrasinusoidal aggregates & $38(58)$ & $47(57)$ & $1.04(0.7-1.5)$ \\
Perivascular inflammation & $63(97)$ & $77(93)$ & $2.76(1.6-4.8)^{* *}$ \\
Hepatocyte steatosis & $14(22)$ & $14(17)$ & $1.16(0.7-1.8)$ \\
Ballooning of hepatocytes & $20(31)$ & $11(13)$ & $1.88(1.2-2.9)^{* *}$ \\
Hepatocyte necrosis & $10(15)$ & $15(18)$ & $0.74(0.4-1.5)$ \\
\hline
\end{tabular}

Abbreviation: Adj. OR, odds ratio adjusted re: parasitic burden on the spleen

${ }^{*} P<0.05,{ }^{*} P<0.01$

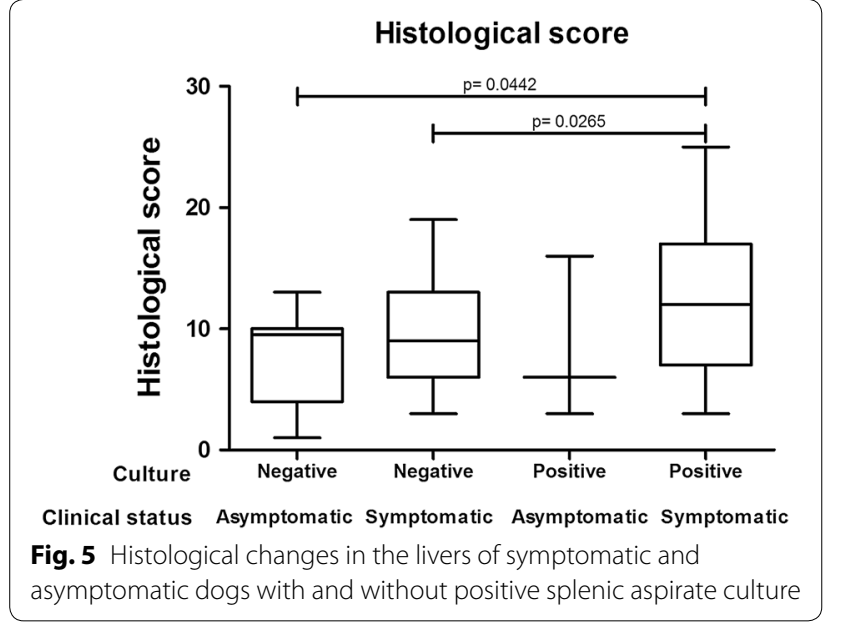

test, $U=7.000, Z=2.64, P=0.0084$ ), and those with mild (Mann-Whitney test, $U=26.00, Z=2.49, P=0.0126$ ) or moderate intralobular granulomas (Mann-Whitney test, $U=8.000, Z=2.59, P=0.0097)$. Serum ALT levels were higher in animals presenting intense portal tract granulomas than in animals without this histological alteration (Mann-Whitney test, $U=26.00, Z=2.52, P=0.0114$, Table 5).

Serum levels of albumin were lower in animals with intense perivascular inflammation than in animals without perivascular inflammation $(U=0.0, Z=1.96$, $P=0.0498)$, as well as in those with mild $(U=8.000$,
$Z=2.83, P=0.0046)$ or moderate perivascular inflammation (Mann-Whitney test, $U=6.000, Z=2.64$, $P=0.0083$, Table 5). Serum globulin levels were higher in animals with a moderate number of intrasinusoidal aggregates than in animals without $(t=2.788$, $P=0.0087)$ this alteration, or those with low numbers (i.e. mild) of intrasinusoidal aggregates $(t=3.697$, $P=0.0007$, unpaired t-test, Table 5).

Serum triglyceride levels were higher in animals with higher numbers of intralobular granulomas than in animals without $(U=11.00, Z=2.72, P=0.0066)$ this alteration, as well as in those with lower numbers (i.e. mild) of intralobular granulomas $(U=8.000, Z=2.72$, $P=0.0065)$. Serum cholesterol levels were higher in the animals that presented intense perivascular inflammation than in those with mild $(U=2.000, Z=2.67$, $P=0.0075)$ or moderate perivascular inflammation (Mann-Whitney test, $U=0.0, \quad Z=2.66, \quad P=0.0077$, Table 6). No significant differences were found among the groups with respect to the other biochemical or hematological tests evaluated.

Our analysis of associations between histological hepatic alterations and PCR for Erlichia and Babesia indicated that dogs with positivity for Ehrlichia presented smaller portal granulomas $(U=287.5, Z=2.03$, $P=0.0423)$ and a more intense intrasinusoidal lymphocyte infiltrate (Mann-Whitney test, $U=218.0, Z=2.43$, $P=0.0152$,) compared to negative animals. No statistical differences were found in relation to the other parameters evaluated. 
Table 4 Associations between histological alterations in the liver and hematological parameters

\begin{tabular}{|c|c|c|c|c|c|c|c|c|}
\hline \multirow[t]{2}{*}{ Histological change } & \multicolumn{2}{|c|}{ Red blood cells } & \multicolumn{2}{|c|}{ Hemoglobin } & \multicolumn{2}{|c|}{ Hematocrit } & \multicolumn{2}{|c|}{ Leukocytes $\left(\times 10^{3}\right)$} \\
\hline & Median & p25-p75 & Median & p25-p75 & Median & p25-p75 & Median & p25-p75 \\
\hline \multicolumn{9}{|l|}{ Portal inflammation } \\
\hline Absent & 5.78 & $5.72-5.84(n=2)$ & 12.5 & $12.3-12.7(n=2)$ & 37.4 & $37.1-37.7(n=2)$ & 11.4 & $11.2-11.6(n=2)$ \\
\hline Discreet & $5.07^{*}$ & $4.23-5.95(n=39)$ & $10.6^{*}$ & $9.0-12.8(n=39)$ & $31.7^{*}$ & $27.0-37.9(n=39)$ & 14.1 & $10.3-17.5(n=39)$ \\
\hline Moderate & $4.13^{*}$ & $3.88-5.26(n=15)$ & $9.7^{*}$ & $8.7-11.5(n=15)$ & $30^{*}$ & $24.5-35.5(n=15)$ & 13.7 & $9.0-18.5(n=15)$ \\
\hline Intense & 2.73 & $2.7-3.2(n=3)$ & 6.6 & $4.8-7.5(n=3)$ & 18.2 & $15.0-21.0(n=3)$ & 13.2 & $7.5-16.2(n=3)$ \\
\hline \multicolumn{9}{|c|}{ Perivascular inflammation } \\
\hline Absent & 5.72 & $3.9-5.84(n=3)$ & 12.3 & $8.8-12.7(n=3)$ & 37.1 & $25.0-37.7(n=3)$ & 11.6 & $11.2-15.8(n=3)$ \\
\hline Discreet & $5.07^{*}$ & $4.28-5.94(n=33)$ & $10.6^{*}$ & $9.0-12.8(n=33)$ & $32.0^{*}$ & $27.6-38.4(n=33)$ & 13.9 & $10.2-17.4(n=33)$ \\
\hline Moderate & $4.68^{*}$ & $3.96-5.66(n=19)$ & $10.3^{*}$ & $9.0-11.8(n=19)$ & $30.4^{*}$ & $25.8-36.7(n=19)$ & 13.7 & $9.0-18.5(n=19)$ \\
\hline Intense & 2.90 & $2.7-3.68(n=4)$ & 6.85 & $5.25-8.3(n=4)$ & 18.9 & $15.8-23.3(n=4)$ & 14.7 & $9.52-32.25(n=4)$ \\
\hline
\end{tabular}

Abbreviations: $\mathrm{p} 25,25$ th percentile; $\mathrm{p} 75,75$ th percentile

${ }^{*} P<0.05,{ }^{* *} P<0.01$

\section{Discussion}

The present study found an association between a positive splenic culture for $L$. infantum and parasite burden in the spleen in dogs with inflammation in the liver. While hepatic portal and perivascular inflammation, as well as granulomas, were linked to higher parasite loads in the spleen, intrasinusoidal lymphocytosis, intrasinusoidal mononuclear inflammatory cells aggregates and Kupffer cell hypertrophy were associated with lower splenic parasite loads. Additionally, liver inflammation was also correlated with clinical, hematological and biochemical alterations. No significant associations were found between histological parasitism of the liver and the frequency of the other histological hepatic alterations, or granuloma organization.

It is interesting to note that different patterns of inflammatory infiltrate in the liver seem to be associated with different stages of infection, as well as difference in the immune response to Leishmania [14]. It has been shown in mice and hamsters that sequential increases and decreases in parasite burden in the liver are followed by a sustained increase in splenic parasitism [14]. Hence, intra-sinusoidal leukocytosis and the presence of leukocyte aggregates in association with a low parasite burden in the spleen may represent an early stage of parasite dissemination in internal organs. Another possible explanation is that this pattern of inflammatory infiltrate in the liver may represent a more effective immune response to infection.

Chronic inflammation has been associated with the persistence of infection [15]. Furthermore, evidence indicates that the organization and cell composition of chronic inflammatory infiltrate may be associated with protection against or permissiveness to the infecting agent $[19,24]$. For instance, reports in the literature have described well-organized granulomas in association with resistance to Leishmania in experimental models, as well as in human disease [12, 24]. Herein, the frequency and morphological characteristics of granulomas bore no relation to clinical manifestations in the animals evaluated, nor was any association with the control of parasitism observed. In contrast, well-organized granulomas containing many parasites in their interior were observed. Granulomas are functionally dynamic structures that may initially contain parasites, which they may be able to eliminate, or not. Although the formation of granulomas may constitute a step towards infection control, parasites may be able to subvert granulomas to favor survival and growth [24]. Hence, as shown in an experimental model of leishmaniasis [24] as well as in tuberculosis, granulomas in dogs may also be permissive or non-permissive to Leishmania, and can either eliminate parasites, or favor their survival $[25,26]$. The fact that Kupffer cell hypertrophy was found to be associated with decreased parasitism in the spleen may suggest that granulomas represent a second line of defense after Kupffer cell activation failed to kill parasites. It follows that the presence of granulomas may provide evidence that the first-line attempt at parasite elimination was unsuccessful, as a subsequent chronic inflammatory response is mounted. An improved characterization of cellular phenotype, in addition to the production of cytokines and microbicidal factors by intra-sinusoidal leukocytes, may help to better understand liver inflammation in VL.

We also found that symptomatic dogs with a positive spleen culture had a higher frequency of inflammatory changes in the liver compared to the other groups. In addition, these animals were more likely to have a higher overall clinical score. While similar hepatic alterations have been described in the literature $[9,16,17,27-29]$, 


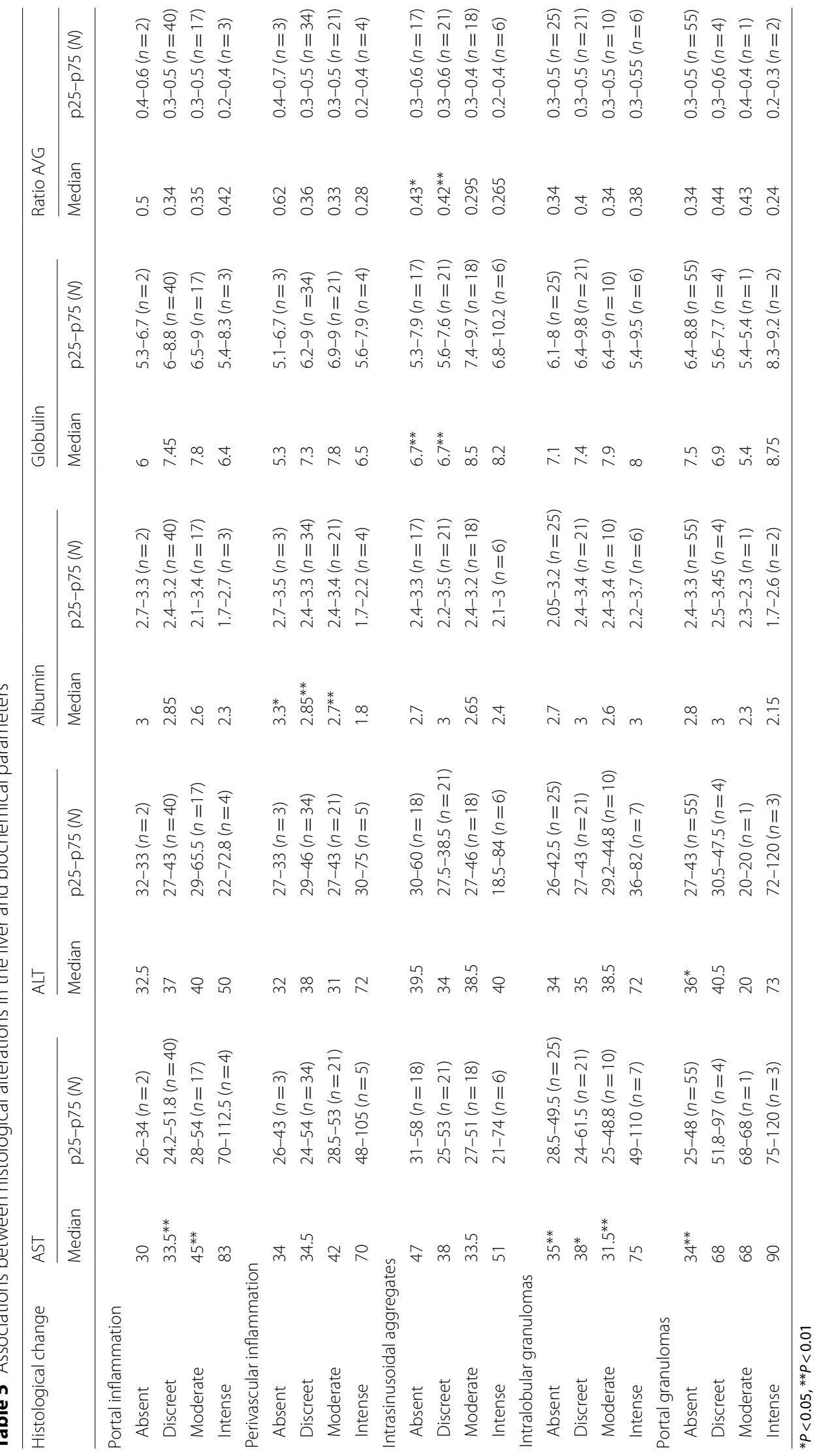


Table 6 Associations between histological alterations in the liver and biochemical parameters such as triglyceride and cholesterol

\begin{tabular}{|c|c|c|c|c|}
\hline \multirow[t]{2}{*}{ Histological change } & \multicolumn{2}{|c|}{ Triglyceride } & \multicolumn{2}{|c|}{ Cholesterol } \\
\hline & Median & p25-p75 (N) & Median & $\mathrm{p} 25-\mathrm{p} 75(\mathrm{~N})$ \\
\hline \multicolumn{5}{|c|}{ Perivascular inflammation } \\
\hline Absent & 28 & $25-31(n=2)$ & 159.5 & $157-162(n=2)$ \\
\hline Discreet & 46 & $31-64(n=31)$ & $165^{* *}$ & $130-233(n=31)$ \\
\hline Moderate & 57.5 & $44.2-81.2(n=18)$ & $177.5^{* *}$ & $157.8-215.8(n=18)$ \\
\hline Intense & 82 & $41-83(n=3)$ & 332 & $269-448(n=3)$ \\
\hline \multicolumn{5}{|c|}{ Intralobular granulomas } \\
\hline Absent & $44.5^{* *}$ & $32.5-66.2(n=22)$ & 169 & $153-219.5(n=22)$ \\
\hline Discreet & $47.5^{* *}$ & $31.8-59.5(n=18)$ & 167 & $134.8-202(n=18)$ \\
\hline Moderate & 55 & $41-69.5(n=9)$ & 175 & $139-222(n=9)$ \\
\hline Intense & 83 & $72-102(n=5)$ & 236 & $130.5-360.5(n=5)$ \\
\hline
\end{tabular}

Abbreviation: $\mathrm{p} 25,25$ th percentile; $\mathrm{p} 75,75$ th percentile

** $P<0.01$

differences in clinical classification and the presence of infection may explain some of the discrepancies between our results and those reported by other studies, such as the fact that we did not use uninfected control animals for comparisons. The present study considered liver alterations only in dogs naturally infected by Leishmania from an endemic area, which presented the full clinical spectrum of disease.

In addition to clinical signs, the present study also evaluated hematological and biochemical parameters, revealing an association between histological inflammatory changes and laboratory alterations. A previous study reported a positive correlation between the progression of Kupffer cell hyperplasia and hypertrophy and increases in serum globulin and total protein levels, which was found to be negatively correlated with serum albumin concentrations [16]. Regarding the other biochemical and hematological alterations, the relationship between these alterations and a more severe clinical picture in dogs with VL has already been described in the literature. However, previous reports did not evaluate these alterations with respect to histological alterations in the liver, but rather in relation to clinical manifestation, parasite load and the disorganization of splenic white pulp, which differs from the criteria evaluated in the present study $[9,30]$.

Our analysis of the presence of co-infections found an association between the size of portal tract granulomas, the intensity of intrasinusoidal lymphocytosis and positivity by PCR for Ehrlichia canis. The relatively scare studies that reported an association between ehrlichiosis and histological changes in the liver found periportal and perivascular mononuclear inflammatory cell infiltrate, sinusoidal microgranulomas, steatosis and sinusoid congestion $[31,32]$. We believe that this warrants further investigation.

\section{Conclusions}

The present findings raise the possibility that dogs exhibit a response profile different from that described in murine models. Our results suggest that the activation of Kupffer cells and increased numbers of lymphocytes in the liver, as well as the formation of aggregates of these cells inside the sinusoids, may be responsible for the elimination of parasites, leading to the containment of infection. In summary, it is possible that granuloma formation may be the result of the failure of the first-line of parasite load and infection control.

\section{Abbreviations}

VL: visceral leishmaniasis; IHC: immunohistochemistry; H\&E: hematoxylin and eosin; DTH: delayed type hypersensitivity; OR: odds ratio; Cl: confidence interval; ALT: alanine aminotransferase; AST: aspartate aminotransferase; RBC: red blood cell; WBC: white blood cell;TP: total protein; ELISA: enzyme-linked immunosorbent assay; iv: intravenous; PCR: polymerase chain reaction; EDTA2Na: ethylenediaminetetraacetic acid, disodium salt; $\mathrm{p} 25$ : 25th percentile; $\mathrm{p} 75$ : 75th percentile.

\section{Acknowledgements}

Authors would like to thank Dr. Ricardo Riccio for his assistance with the statistical analysis of the data. The authors would like to thank Andris K. Walter for English language revision and manuscript copyediting assistance.

\section{Authors' contributions}

WLCS and LARF designed the study and performed the animal experiments and post-mortem examinations. MSS carried out the molecular studies. WLT and ISL carried out the immunohistochemical analysis and image analyses. ISL, WLCS and LARF wrote the manuscript. All authors read and approved the final manuscript.

\section{Funding}

This work was supported by Fundação de Amparo à Pesquisa do Estado da Bahia (Fapesb. http://www.fapesb.ba.gov.br) Grant No. APR0434/2005, Grant No. DTE0037/2011 and the Oswaldo Cruz Foundation (Fiocruz; http://porta I.fiocruz.br/pt-br) PAPES V, grant 403470/2008-0. None of the funders had any role in study design, data collection or interpretation, nor the decision to submit this work for publication. 


\section{Availability of data and materials}

Data supporting the conclusions of this article are provided within the article. The datasets used and/or analyzed are available from the corresponding author upon reasonable request.

\section{Ethics approval and consent to participate}

This study was performed in strict accordance with the recommendations of the Brazilian Federal Law on Animal Experimentation (Law 11794) (http:// www.planalto.gov.br/ccivil 03/_ato2007-2010/2008/lei/l11794.htm) and with the Brazilian Ministry of Health manual for the surveillance and control of visceral leishmaniasis (Brasil, 2014). The present study protocol was approved by the Institutional Review Board for the Use of Animal Experimentation in Research (CPqGM-FIOCRUZ, Ceua, license number: 015/2009).

\section{Consent for publication}

Not applicable.

\section{Competing interests}

The authors declare that they have no competing interests.

\section{Author details}

${ }^{1}$ Instituto Gonçalo Moniz, Fundação Oswaldo Cruz, Salvador, BA, Brazil.

2 Departamento de Patologia Geral, Instituto de Ciências Biológicas, Universidade Federal de Minas Gerais, Belo Horizonte, MG, Brazil.

\section{Received: 30 April 2019 Accepted: 16 September 2019} Published online: 16 October 2019

\section{References}

1. Ministério da Saúde, Brasil. Manual de Vigilância e Controle da Leishmaniose Visceral. 2014. http://bvsms.saude.gov.br/bvs/publicacoe s/manual_vigilancia_controle_leishmaniose_visceral_1edicao.pdf. Accessed 9 May 2018.

2. Harhay MO, Olliaro PL, Costa DL, Costa CHN. Urban parasitology: visceral leishmaniasis in Brazil. Trends Parasitol. 2011;27:403-9.

3. de Queiroz NMGP, da Silveira RCV, de Noronha ACF, Oliveira TMFS, Machado RZ, Starke-Buzetti WA. Detection of Leishmania (L.) chagasi in canine skin. Vet Parasitol. 2011:178:1-8.

4. Dantas-Torres F. The role of dogs as reservoirs of Leishmania parasites, with emphasis on Leishmania (Leishmania) infantum and Leishmania (Viannia) braziliensis. Vet Parasitol. 2007;149:139-46.

5. Ciaramella P, Oliva G, de Luna R, Gradoni L, Ambrosio R, Cortese L, et al. A retrospective clinical study of canine leishmaniasis in 150 dogs naturally infected by Leishmania infantum. Vet Rec. 1997;141:539-43.

6. Barrouin-Melo SM, Larangeira DF, de Andrade Filho FA, Trigo J, Julião FS, Franke CR, et al. Can spleen aspirations be safely used for the parasitological diagnosis of canine visceral leishmaniosis? A study on assymptomatic and polysymptomatic animals. Vet J. 2006:171:331-9.

7. Guerra LL, Teixeira-Carvalho A, Giunchetti RC, Martins-Filho OA, Reis AB, Corrêa-Oliveira R. Evaluation of the influence of tissue parasite density on hematological and phenotypic cellular parameters of circulating leukocytes and splenocytes during ongoing canine visceral leishmaniasis. Parasitol Res. 2009;104:611-22.

8. de Trópia Abreu R, das Carvalho MG, Carneiro CM, Giunchetti RC, Teixeira-Carvalho A, Martins-Filho OA, et al. Influence of clinical status and parasite load on erythropoiesis and leucopoiesis in dogs naturally infected with Leishmania (Leishmania) chagasi. PLoS One. 2011;6:e18873.

9. Lima IS, Silva JS, Almeida VA, Leal FG, Souza PAN, Larangeira DF, et al. Severe clinical presentation of visceral leishmaniasis in naturally infected dogs with disruption of the splenic white pulp. PLoS One. 2014:9(2):e87742.

10. Duarte MI, Corbett CE. Histopathological patterns of the liver involvement in visceral leishmaniasis. Rev Inst Med Trop Sao Paulo. 1987;29:131-6.

11. El Hag IA, Hashim FA, EI Toum IA, Homeida M, El Kalifa M, El Hassan AM. Liver morphology and function in visceral leishmaniasis (Kala-azar). J Clin Pathol. 1994:47:547-51.
12. Pampiglione S, La Placa M, Schlick G. Studies on Mediterranean leishmaniasis I. An outbreak of visceral leishmaniasis in northern Italy. Trans R Soc Trop Med Hyg. 1974;68:349-59.

13. Pampiglione S, Manson-Bahr PEC, Giungi F, Giunti G, Parenti A, Trotti GC. Studies on mediterranean leishmaniasis: 2. asymptomatic cases of visceral leishmaniasis. Trans R Soc Trop Med Hyg. 1974;68:447-53.

14. Engwerda CR, Kaye PM. Organ-specific immune responses associated with infectious disease. Immunol Today. 2000;21:73-8.

15. Engwerda CR, Ato M, Kaye PM. Macrophages, pathology and parasite persistence in experimental visceral leishmaniasis. Trends Parasitol. 2004;20:524-30.

16. Giunchetti RC, Mayrink W, Carneiro CM, Corrêa-Oliveira R, Martins-Filho OA, Marques MJ, et al. Histopathological and immunohistochemical investigations of the hepatic compartment associated with parasitism and serum biochemical changes in canine visceral leishmaniasis. Res Vet Sci. 2008;84:269-77.

17. Oliveira GGS, Santoro F, Sadigursky M. The subclinical form of experimental visceral leishmaniasis in dogs. Mem Inst Oswaldo Cruz. 1993;88:243-8

18. Melo FA, Moura EP, Ribeiro RR, Alves CF, Caliari MV, Tafuri WL, et al. Hepatic extracellular matrix alterations in dogs naturally infected with Leishmania (Leishmania) chagasi. Int J Exp Pathol. 2009;90:538-48.

19. Sánchez MA, Diaz NL, Zerpa O, Negron E, Convit J, Tapia FJ. Organ-specific immunity in canine visceral leishmaniasis: Analysis of symptomatic and asymptomatic dogs naturally infected with Leishmania chagasi. Am J Trop Med Hyg. 2004;70:618-24

20. Dos-Santos WLC, Jesus EE, Paranhos-Silva M, Pereira AM, Santos JC, Baleeiro CO, et al. Associations among immunological, parasitological and clinical parameters in canine visceral leishmaniasis: emaciation, spleen parasitism, specific antibodies and leishmanin skin test reaction. Vet Immunol Immunopathol. 2008;123:251-9.

21. Francino O, Altet L, Sánchez-Robert E, Rodriguez A, Solano-Gallego L, Alberola J, et al. Advantages of real-time PCR assay for diagnosis and monitoring of canine leishmaniosis. Vet Parasitol. 2006;137:214-21.

22. Bulla C, Kiomi Takahira R, Pessoa Araújo J, Aparecida Trinca L, Souza Lopes $\mathrm{R}$, Wiedmeyer CE. The relationship between the degree of thrombocytopenia and infection with Ehrlichia canis in an endemic area. Vet Res. 2004:35:141-6.

23. Tafuri WL, Santos RD, Arantes RM, Gonçalves R, de Melo MN, Michalick MS, Tafuri WL. An alternative immunohistochemical method for detecting Leishmania amastigotes in paraffin-embedded canine tissues. J Immunol Methods. 2004:292:17-23.

24. Murray HW. Tissue granuloma structure-function in experimental visceral leishmaniasis. Int J Exp Pathol. 2001;82:249-67.

25. Coleman MT, Maiello P, Tomko J, Frye LJ, Fillmore D, Janssen C, et al. Early changes by ${ }^{18}$ Fluorodeoxyglucose positron emission tomography coregistered with computed tomography predict outcome after Mycobacterium tuberculosis infection in cynomolgus macaques. Infect Immun. 2014:82:2400-4

26. Lin PL, Maiello P, Gideon HP, Coleman MT, Cadena AM, Rodgers MA, et al. PET CT identifies reactivation risk in Cynomolgus macaques with latent M. tuberculosis. PLoS Pathog. 2016;12:e1005739.

27. Binhazim AA, Chapman WL, Latimer KS, Styles M, Comer K. Canine leishmaniasis caused by Leishmania leishmania infantum in two Labrador retrievers. J Vet Diagn Invest. 1992:4:299-305.

28. Tafuri WL, Tafuri WL, Barbosa AJA, Michalick MSM, Genaro O, FrançaSilva JC, et al. Histopathology and immunocytochemical study of type 3 and type 4 complement receptors in the liver and spleen of dogs naturally and experimentally infected with Leishmania (Leishmania) chagasi. Rev Inst Med Trop Sao Paulo. 1996;38:81-9.

29. Madeira IMVM, Pereira DMO, Sousa AA, Vilela CA, Amorim IFG, Caliari MV, et al. Immunohistochemical study of hepatic fibropoiesis associated with canine visceral leishmaniasis. Int J Exp Pathol. 2016:97:139-49.

30. Reis AB, Martins-Filho OA, Teixeira-Carvalho A, Carvalho MG, Mayrink W, França-Silva JC, et al. Parasite density and impaired biochemical/hematological status are associated with severe clinical aspects of canine visceral leishmaniasis. Res Vet Sci. 2006;81:68-75

31. Nair ADS, Cheng C, Ganta CK, Sanderson MW, Alleman AR, Munderloh $U G$, et al. Comparative experimental infection study in dogs with 
Ehrlichia canis, E. chaffeensis, Anaplasma platys and A. phagocytophilum. PLoS One. 2016;1 1:e0148239.

32. Castro MB, Machado RZ, De Aquino LPCT, Alessi AC, Costa MT. Experimental acute canine monocytic ehrlichiosis: clinicopathological and immunopathological findings. Vet Parasitol. 2004;1 19:73-86.

\section{Publisher's Note}

Springer Nature remains neutral with regard to jurisdictional claims in published maps and institutional affiliations.
Ready to submit your research? Choose BMC and benefit from:

- fast, convenient online submission

- thorough peer review by experienced researchers in your field

- rapid publication on acceptance

- support for research data, including large and complex data types

- gold Open Access which fosters wider collaboration and increased citations

- maximum visibility for your research: over $100 \mathrm{M}$ website views per year

At BMC, research is always in progress.

Learn more biomedcentral.com/submissions 